B I O S C I E N C E

J O U R N A

\title{
BIOLOGICAL TRACE INFORMATION EXTRACTED FROM BIOAEROSOLS USING NGS ANALYSIS
}

\author{
Panyapon PUMKAEO ${ }^{1}$ (D), Wenhao LU² (iD), Youki ENDOU² (iD), Tomofumi MIZUNO² (D), \\ Junko TAKAHASHI ${ }^{3}$ iD, Hitoshi IWAHASHI ${ }^{2}$
}

\begin{abstract}
${ }^{1}$ Division of Science of Biological Resources, United Graduate School of Agricultural Science, Gifu University, Tokai National Higher Education and Research System, Gifu-shi, Gifu, Japan.

${ }^{2}$ Faculty of Applied Biological Sciences, Gifu University, Tokai National Higher Education and Research System, Gifu-shi, Gifu, Japan.

${ }^{3}$ Biomedical Research Institute, National Institute of Advanced Industrial Science and Technology (AIST), Tsukuba, Ibaraki, Japan.
\end{abstract}

Corresponding author:

Panyapon Pumkaeo

Email: ppumkaeo@gmail.com

How to cite: PUMKAEO, P., et al. Biological trace information extracted from bioaerosols using NGS analysis. Bioscience Journal. 2021, 37, e37090. https://doi.org/10.14393/BJ-v37n0a2021-53678

\begin{abstract}
Bioaerosols are atmospheric particles with a biological trace, such as viruses, bacteria, fungi, and plant material such as pollen and plant debris. In this study, we analyzed the biological information in bioaerosols using next generation sequencing of the trace DNA. The samples were collected using an Andersen air sampler and separated into two groups according to particulate matter (PM) size: small (PM2.5) and large (PM10). Amplification and sequencing of the bacterial 16S rDNA gene, prokaryotic internal transcribed spacer 1 (ITS1) region and DNA sequence of a plant chloroplast gene $(r b c L)$ were carried out using several sets of specific primers targeting animal and plant sequences. Lots of bacterial information was detected from the bioaerosols. The most abundant bacteria in several samples were of the Actinobacteria (class), Alphaproteobacteria, Bacilli, and Clostridia. For the animal detection using internal transcribed spacer 1, only uncultured fungi were detected in more than half of the hits, with a high number of Cladosporium sp. in the samples. For the plant identification, the ITS1 information only matched fungal species. However, targeting of the $r b c L$ region revealed diverse plant information, such as Medicago papillosa. In conclusion, traces of bacteria, fungi, and plants could be detected in the bioaerosols, but not of animals using our primers.
\end{abstract}

Keywords: Bioaerosol. Biological Trace Information. Next Generation Sequencing.

\section{Introduction}

Aerosols are tiny particles suspended in the atmosphere. These small particles that drift in the air comprise many kinds, such as resuspended soil particles, salt particles formed from ocean spray, atmospheric clouds of water droplets or ice particles, and smoke from power generators or some industrial processes. Air pollution recently have been occurred in many countries around the world. Air pollutants such as particulate matter (PM) can affect earth's climate (Samset 2016). Therefore, PM such as PM10 and PM2.5 are commonly used as air quality indicators. In addition, biological components (e.g., allergens and microbial compounds) are found in PM. Bioaerosols are PM that is associated with compounds of biological origin (Douwes et al. 2003). They include living organisms, such as viruses, bacteria, and fungi, and parts of plant reproductive particles like pollen (Hinds 1999). Bioaerosols play an important role in the wind dispersal of the reproductive parts of some species (e.g., plant pollen, fungal spores, and pathogens of crop plants), and as such can spread plant diseases (Brown and Hovmøller 2002). Pollen, fungi, and bacteria are the main microscopic biological entities present in the outdoor air, where they cause allergy symptoms and disease 
transmission and have a significant role in the atmosphere dynamics (Bowers et al. 2011). There is presently a need for establishing a map of biological aerosol transmissions in the world. Fortunately, we already have the technology to monitor DNA sequences in bioaerosols without having to grow the constituent organisms in the samples, with next-generation sequencing (NGS) playing a significant role for this purpose.

In the past, most bioaerosol studies had focused only on the bacterial and fungal communities, as the monitoring was studied by growing the microbes present in the bioaerosols (Fröhlich-Nowoisky et al. 2009; Bowers et al. 2011; Hussin et al. 2011; Fröhlich-Nowoisky et al. 2012; Womack et al. 2015). In this present study, we collected the particles in bioaerosols from Tsukuba, Japan and analyzed their DNA using NGS, with the aim being to extract trace information regarding animals, plants, and bacteria in bioaerosols of this region.

\section{Material and Methods}

\section{Sample collection and DNA extraction}

Andersen AN-200 samplers (T-Dylec Co., Japan) were placed on the roof of the National Institute of Advanced Industrial Science and Technology (AIST) building in Tsukuba, Japan, at approximately $50 \mathrm{~m}$ above ground. Bioaerosol samples were collected about 49 days from November 29, 2013, to January 16, 2014. The circular glass plates which covered with a polymer membrane for capturing samples from the air were place on each stage of Anderson air sampler. A series of eight plates were marked according to the size of dust particles that could be held respectively; that is, greater than $11 \mu \mathrm{m}$ and less than $0.65 \mu \mathrm{m}$. These eight plates from the Anderson air samplers were divided into two groups: the small group (plates 1, 2, 3, and 4) and the large group (plates 5, 6, 7, and 8). Particles of between 2.5 and $10 \mu \mathrm{m}$ in diameter (PM2.5-10) were defined as "cross particles" and those of less than $2.5 \mu \mathrm{m}$ in diameter (PM2.5) were defined as "fine particles" (Anderson et al. 2012). The particle sizes of the small group varied from 0.65 to $2.1 \mu \mathrm{m}$, corresponding to PM2.5, and those of the large group varied from 3.3 to $11.0 \mu \mathrm{m}$, corresponding to PM10. In total, 12 air samples were obtained during the sampling periods. The DNA extractions were performed with the Extrap Soil DNA Kit Plus ver.2 (Thermo Fisher Scientific, Germany) according to the manufacturer's protocol.

\section{PCR amplification of four regions}

The prokaryote $16 \mathrm{~S}$ rDNA gene was amplified using universal bacterial $16 \mathrm{~S}$ rDNA primers. For animal identification, the sequence information of an internal transcribed spacer (ITS) region was targeted using the universal primer set ITS1F/ITS2. Another universal primer set (ITS5/ITS2) was used to target the plant ITS region. Both ITS primer sets (ITS1F/ITS2 and ITS5/ITS2) were based on the conserved region of the 18S, 5.8S, and 28S rDNA genes for amplifying the ITS1 region (White et al. 1990). The ITS region has been reported as a standard DNA barcode marker in plants (Li et al. 2011) and has also been demonstrated as a DNA barcode in animals (Salvi and Mariottini 2012) and protists (Stern et al. 2012). The ribulose-bisphosphate carboxylase $(r b c L)$ gene was also targeted for the identification of plants (Table 1).

Table 1. Universal primers used in this study.

\begin{tabular}{|c|c|c|}
\hline Primers & Organism & References \\
\hline 27F: 5'-AGAGTTTGATCMTGGCTCAG-3 & & (Hogg and Lehane 1999) \\
\hline 519R: 5'-GWATTACCGCGGCKGCTG-3' & Bacterla & (Turner et al. 1999) \\
\hline ITS1F: 5'-CTTGGTCATTTAGAGGAAGTAA-3' & Animal & (Gardes and Bruns 1993) \\
\hline ITS2: 5'-GCTGCGTTCTTCATCGATGC-3' & Animal & (White et al. 1990) \\
\hline ITS5: 5'-GGAAGTAAAAGTCGTAACAAGG-3' & Plant & (White et al. 1990) \\
\hline ITS2: 5'-GCTGCGTTCTTCATCGATGC-3' & Plant & (White et al. 1990) \\
\hline $\begin{array}{c}r b c L \text { F: 5'ATGTCACCACAAACAGAGACTAAAGC-3' } \\
r b c L \text { R: 5'GTAAAATCAAGTCCACCRCG-3' }\end{array}$ & Plant & $\begin{array}{c}\text { (Soltis et al. 1992) } \\
\text { (Kress and Erickson 2007) }\end{array}$ \\
\hline
\end{tabular}


The optimal PCR conditions for obtaining amplicons of relatively high quantity and concentration was optimized by preliminary experiments. PCR amplification was carried out using the GoTaq ${ }^{\circledR}$ Green Master Mix (Promega) in a $25 \mu \mathrm{L}$ reaction volume made up of $12.5 \mu \mathrm{L}$ of GoTaq ${ }^{\circledR}$ Green Master Mix (2x solution), $6.1 \mu \mathrm{L}$ of nuclease-free water, $4 \mu \mathrm{L}$ of DNA template, and $1.2 \mu \mathrm{L}$ each of the upstream and downstream primers. The PCR reactions were performed in GeneAmp ${ }^{\circledR}$ PCR System 2700 (Applied Biosystems) using a program which consisted of an initial denaturation step of 4 min at $95^{\circ} \mathrm{C}$, followed by $30 \mathrm{cycles}$ of $30 \mathrm{sec}$ at $94^{\circ} \mathrm{C}, 1 \mathrm{~min}$ at $55^{\circ} \mathrm{C}, 1 \mathrm{~min}$ at $72^{\circ} \mathrm{C}$ and a final step of $10 \mathrm{~min}$ at $72^{\circ} \mathrm{C}$.

\section{Next-generation sequencing}

After PCR amplification and purification, the amplicons were analyzed by Roche 454 sequencing using a Series GS FLX+ sequencer (Hokkaido System Science Co., Ltd., Japan). After completion of the sequencing run, data processing was done using the GS Run Processor application. The data were subjected to read quality filtering, where raw pyrosequencing reads were filtered based on ambiguous bases, length, and average quality. The default parameters removed all reads that were shorter than $100 \mathrm{bp}$, contained ambiguous bases, or had average quality scores of 25 .

\section{Basic Local Alignment Search Tool analysis}

A local Basic Local Alignment Search Tool (BLAST) analysis was carried out using BLAST+ executables downloaded from the National Center for Biotechnology Information (NCBI) website. The BLAST nucleotide database was used to compare the query sequence against known sequences. All data were accessed from the NCBI FTP download website, which included 100 Gigabytes of all known nucleotide sequences up to March 8, 2015, as well as the embedded taxonomy database. After the BLAST analyses, all candidate subject sequences that were the most similar to the query sequences (samples) were listed. The Bios command was as follows: >blastn -query samplename. fasta - $d b$ databasenamedb -out result.xls -max_target_seqs 5 outfmt "7 qseqid ssqid pident length evalue score mismatch qseq sseq sscinames."

\section{Results}

\section{Information of bacterial 16S rDNA sequences}

The prokaryotic compositions in six of the sample plates ( 3 of the large and 3 of the small particle size groups) were analyzed. Of the large dust size samples, sample1_MID-107 was collected over 16 days of monitoring, whereas Sample1_MID-106 and Sample1_MID-105 were collected over 12 and 21 days, respectively. Sample2_MID-107, Sample2_MID-106, and Sample2_MID-105 were the small dust size samples, where the number designations indicate the same periods of collection as indicated for the large samples (Figures 1 and 2). The number of read included in downstream analyses was 1,341, 1,173, 2,209 for sample1_MID-107, sample1_MID-106 and sample1_MID-105, respectively and 1,415, 558, 2,823 for sample2_MID-107, sample2_MID-106 and sample2_MID-105, respectively. The 16S rDNA sequences were divided into 505 phylotypes (data do not show), where 41 classes were of bacterial origin. The main classes found in all the samples were Actinobacteria (class), Alphaproteobacteria, Bacilli, and Clostridia (Figure 1), which shared more than $97 \%$ identity. A total of 181 families were also classified, with the bacteria of highest abundance being the Clostridiacea, Lactobacillaceae, and Methylococcaceae (Figure 2). 


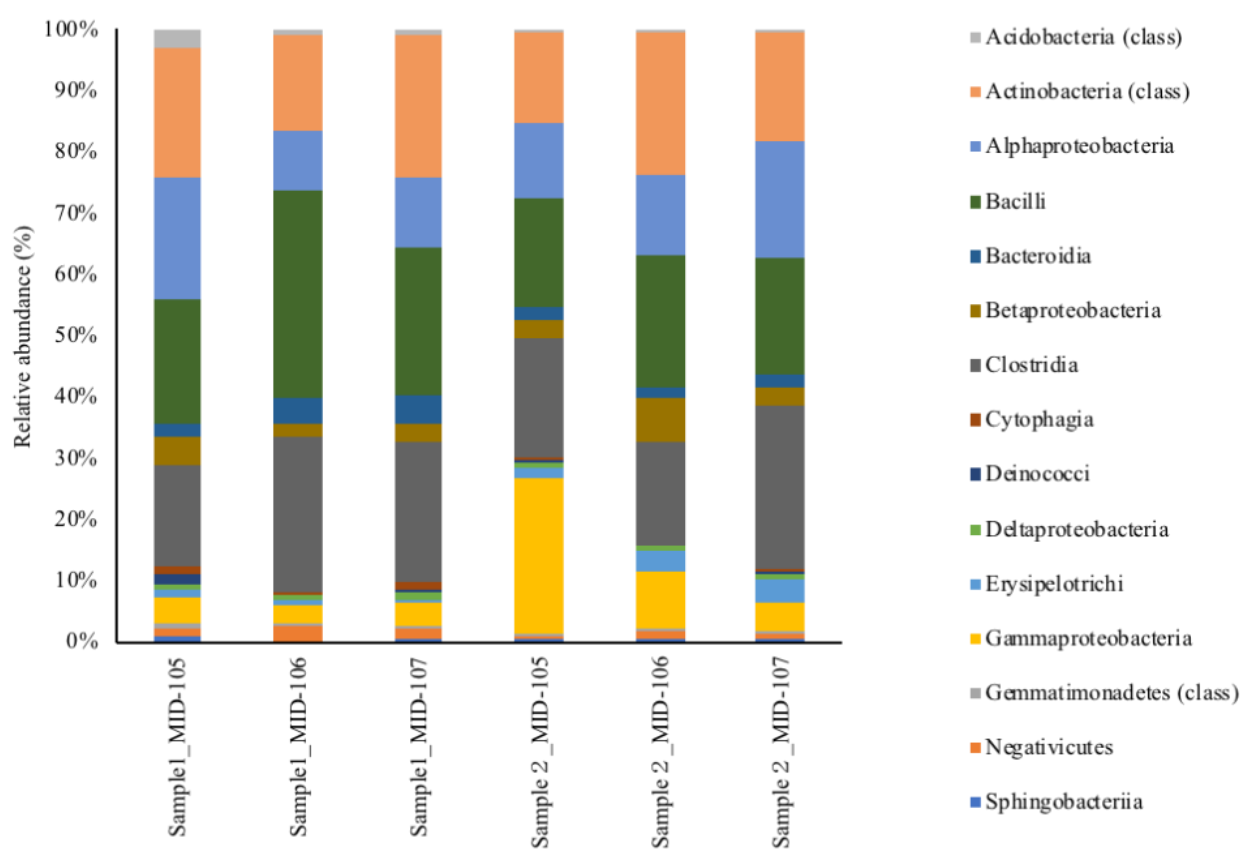

Figure 1. Taxonomic compositions of bacterial 16S rDNA sequences in bioaerosols at the class level. Sample1: large-sized dust sample; Sample2: small-sized dust sample; MID-107: collection period from November 29, 2013 to December 14, 2013; MID-106: collection period from December 15, 2013 to December 26, 2013; and MID-105: collection period from December 26, 2013 to January 16, 2014.
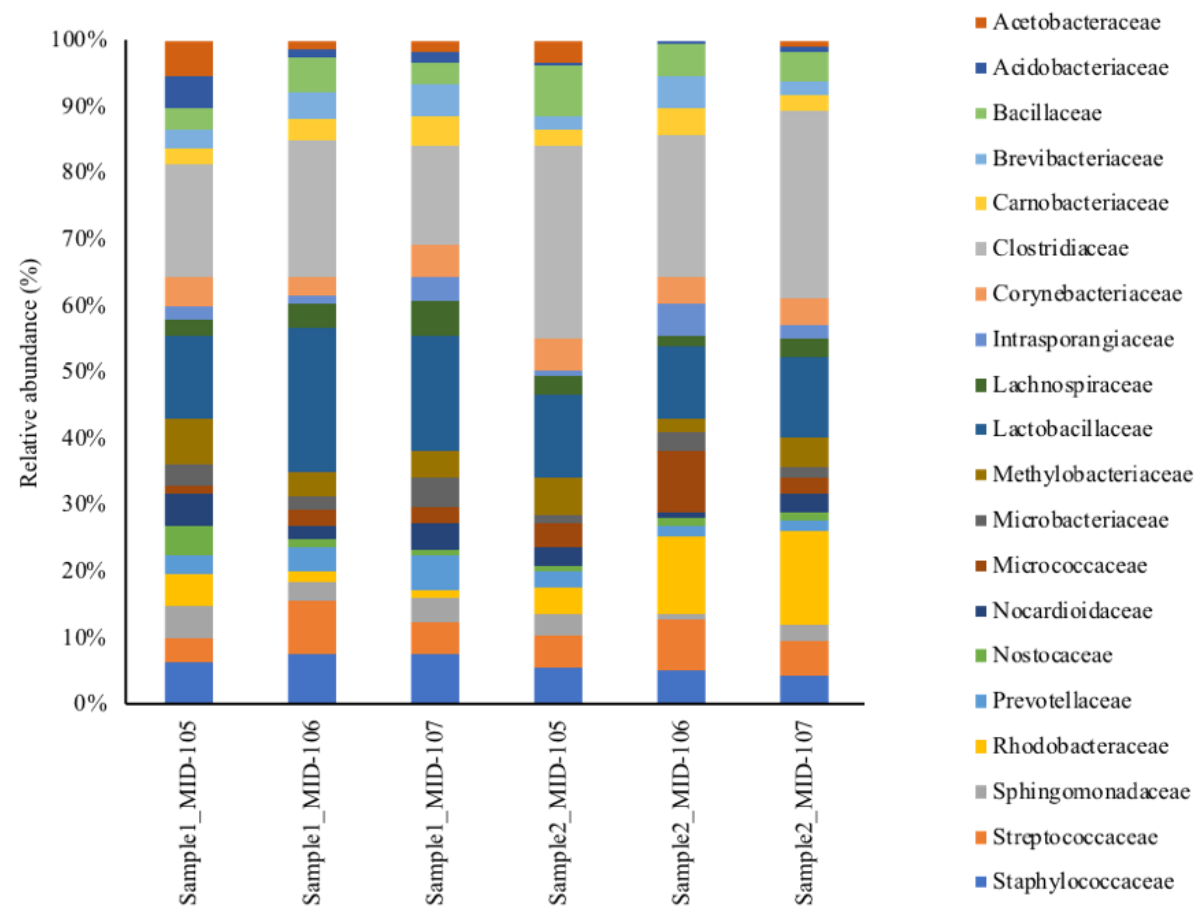

Figure 2. Taxonomic compositions of bacterial $16 \mathrm{~S}$ rDNA sequences in bioaerosols at the family level. Sample1: large-sized dust sample; Sample2: small-sized dust sample; MID-107: collection period from November 29, 2013 to December 14, 2013; MID-106: collection period from December 15, 2013 to December 26, 2013; and MID-105: collection period from December 26, 2013 to January 16, 2014.

\section{Information of animals}

The ITS region amplified with the ITS1F/ITS2 primer set is a known candidate barcode region for identifying animal species (Smith et al. 2007). The number of read included in downstream analyses was 
4,745 for small group and 4,568 for large group. However, we could find only fungal sequences using this primer set. The fungal sequences traced out were identified as the Cladosporium sp. and Trametes sp. which were highly represented in all the samples (Figure 3). More than half of the hits belonged to uncultured fungi. We did not prove that the ITS region targeted by ITS1F/ITS2 can be used to find animal species. Our results only showed that the fungal DNA was highly abundant, likely erasing the information of animal DNA.

A

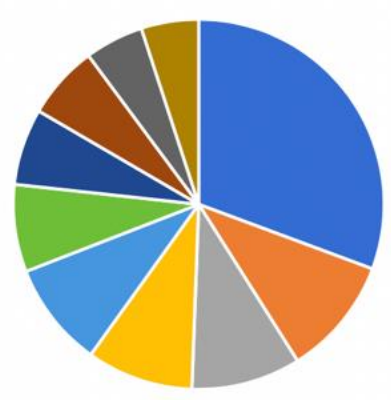

B

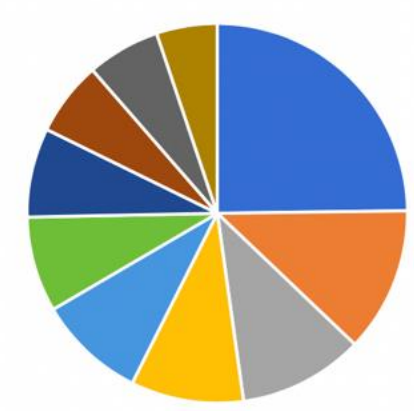

- Cladosporium sp. 1111TES11K2

" uncultured Cadophora

" uncultured Basidiomycota

" Peniophora incarnata

" Strobilurus sp. HT05

" Alternaria alternata

- Trametes sp. SQOI

- Oxyporus cuneatus

- Bjerkandera fumosa

" uncultured Cladosporium

Figure 3. Taxonomic compositions of animal ITS region sequences in bioaerosols. A - small group; B - large group. The universal primer set used was ITS1F/ITS2.

A

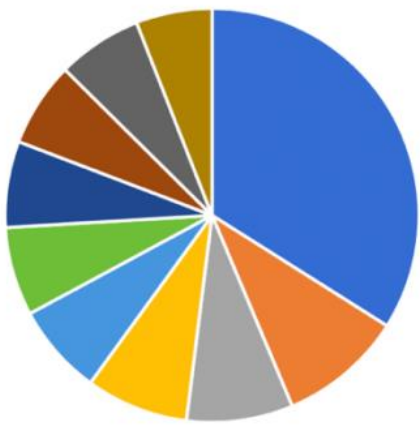

B

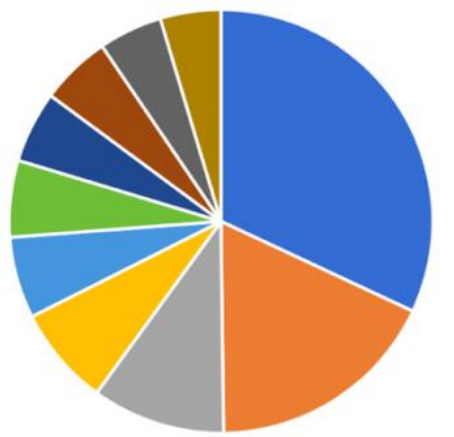

- Cladosporium sp. PP102B

- Ascomycota sp. UNEX FECRGA $2012 E 320$

- Cytospora mali

- Peniophora incarmata

- uncultured Basidiomycota

- Skjabinolecithum spasskii

- Trametes sp. SQ0I

- uncultured Cladosporium

- Vuilleminia comedens

- Saperda carcharias

- Sistotrema sernanderi

" Trametes sp. SQ01

- Trametes versicolor

- uncultured Basidiomycota

- Cladosporium sp. PP102B

Lenzites betulinus

- Strobilurus sp. HT05

- Bjerkandera fumosa

- Cerrena unicolor

- Trametes versicolor f. antarctica

Figure 4. Taxonomic compositions of plant ITS region sequences in bioaerosols. A - small group; B - large group. The universal primer set used was ITS5/ITS2. 


\section{Information of plants}

The ITS region targeted by ITS5/ITS2 can also be a candidate DNA barcode to identify plant species (Chase and Fay 2009). The number of read included in downstream analyses was 5,746 for small group and 5,484 for large group. However, we again could only detect fungal information, such as that of Cladosporium sp., Ascomycota sp., Trametes sp. and Sistotrema sermamderi (Figure 4). The rbcL gene is localized in chloroplast DNA and can be a candidate barcode for detecting plant species. The number of read included in downstream analyses was 4,334 for small group and 5,245 for large group. Plant sequences were indeed detected in the bioaerosols, where 45 and 57 species were found in the large and small subgroups, respectively. Medicago papillosa was a dominant species in both the large and small groups, and a considerably high quantity of Oryza rufipogon (wild rice) was also found in both groups (Figure 5). The BLAST results also revealed five Quercus species with exactly the same sequence in the $r b c L$ gene region; namely, Quercus salicina, Quercus glauca, Quercus gilva, Quercus acuta, and Quercus oxyodon.

A

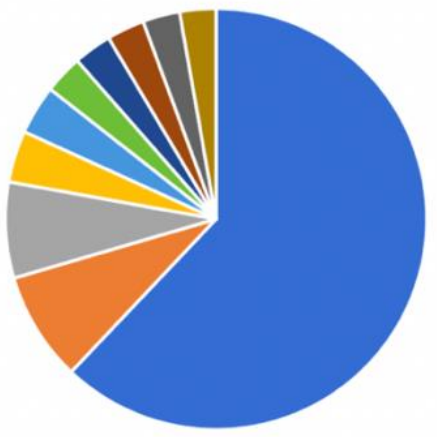

B

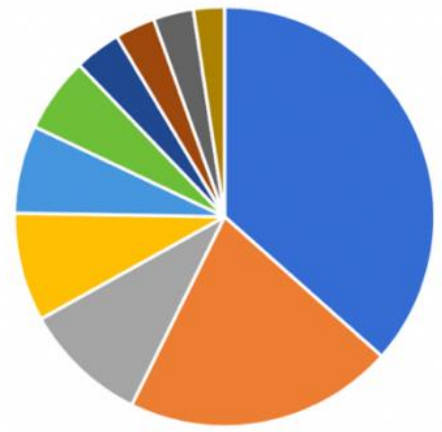

- Medicago papillosa

- Phleum pratense

- Marchantia polymorpha subsp. ruderalis

- Cynodon dactylon

- Pseudosasa japonica

- Cymbopogon jwarancusa

- Fagopyrum esculentum subsp. ancestrale

- Rhynchostegium riparioides

- Cryptomeria japonica

- Glycine max

Figure. 5. Taxonomic compositions of plant $r b c L$ region sequences in bioaerosols. A - small group; B - large group. The universal primer set used was $r b c L_{-} F / r b c L \_R$.

\section{Discussion}

In this study, we have presented the results of 49 days of bioaerosol monitoring at Tsukuba, Japan. The characteristics of the airborne bacteria, identification of eukaryotes as well as fungi, and diversity of plants in the bioaerosols are discussed below. For bacteria, the hits of reads by days showed that the quantities of bacterial DNA appeared equally, except for the smaller subgroup Sample2_MID-106, which contained only half the amount of DNA compared with the larger subgroup (data not shown). It was obvious that the results of bacteria identification had no distinctions either among the different dates or between the small and large groups. Actinobacteria (class), Alphaproteobacteria, Bacilli, and Clostridia were found in all the dust samples (Figure 1).

The Bacilli are commonly identified in bioaerosols (Srivastava et al. 2012), and the Actinobacteria have also been detected in dust samples collected at high altitudes over the Noto Peninsula, Japan (Maki et al. 2017). These results suggest that our sampled bioaerosols are typical of those found in Japan.

In our identification of animals and plants using the ITS targeted by ITS1F/ITS2 and ITS5/ITS2, respectively, all the species traced out were fungi. The dominance of species closely related to Cladosporium 
sp., Sistotrema sernanderi, and Trametes sp. SQ01 in our samples agreed with other works. For example, Cladosporium sp. was shown by NGS to be the most abundant species among airborne fungal communities in urban areas (Fröhlich-Nowoisky et al. 2009) and across the continental United States (Barberán et al. 2015). Cladosporium sp. was also the most common fungal genus associated with symptoms of respiratory tract allergies in humans (Kalogerakis et al. 2005).

The two ITS universal primer sets showed different results for one sample; that is, the Cladosporium genus could be subdivided with ITS1F/ITS2 but not with ITS5/ITS2. More than half of the hits were of uncultured fungi. A similar phenomenon was also seen in the bacterial identification, where uncultured bacteria (or marked as "no rank") were also detected. In fact, it was described that only $1 \%$ of microorganisms from the environment are culturable on media, and approximately $99 \%$ are nonculturable and thus unable to be detected or identified under laboratory conditions (Torsvik et al. 1990). In order to identify the animal information in bioaerosols, we have to find alternative DNA regions as barcodes. Such efforts have already been initiated by many researchers (Vences et al. 2005; Ficetola et al. 2010; Nijman and Aliabadian 2010; Luo et al. 2011). The mitochondrial Cytochrome c Oxidase I gene (COI) has been used extensively as the standard 'taxon barcode' for phylogenetic classification of most animal groups (Hebert et al. 2003). COI region will be using in our next long -term monitoring of bioaerosol in the atmosphere and will definitely improve the quality and the success of identify animal information in bioaerosols.

Using $r b c L$, plant information could be obtained from the bioaerosols. The most abundant plant was Medicago papillosa, being detected in both PM2.5 and PM10. However, many of the other plants were detected in only one sample size, suggesting that plants have their own specifically sized particles scattered in the environment. Thus, the sampling size can be used to distinguish plant information. Medicago papillosa was abundant in the region around the sampling location and the information reflected the regional vegetation. Thus, bioaerosols can be used for monitoring the vegetation after a natural catastrophe and for studying ecological transformations.

\section{Conclusions}

Our study has simultaneously monitored bacteria, plants, and fungi by high-throughput DNA sequencing. Sampling devices at the aerobiological stations can be easily adapted to perform DNA-based analyses. Although we could not detect a trace of any animals in this study, that of plants was accomplished. This plant information may inform us of the geological origin of the bioaerosols, as plants cannot move and may produce colonies in specific geological areas. It is known that the dust raised from areas of desertification is not purely desert dust, and the genomic information contained therein would be useful for environmental protection. Therefore, additional studies to provide more understanding of the complexities of the bioaerosols in different environments are needed, such as information on airborne pathogen transportation, physical and chemical pollutants, and the connection of bioaerosols with biological geography.

Authors' Contributions: PUMKAEO, P.: acquisition of data, analysis and interpretation of data, drafting the article; LU, W.: acquisition of data, analysis and interpretation of data; ENDOU, Y.: acquisition of data, analysis and interpretation of data; MIZUNO, T.: acquisition of data, analysis and interpretation of data, drafting the article; TAKAHASHI, J.: conception and design; IWAHASHI, H.: conception and design. All authors have read and approved the final version of the manuscript.

Conflicts of Interest: The authors declare no conflicts of interest.

Ethics Approval: Not applicable.

Acknowledgments: Not applicable.

\section{References}

ANDERSON, J.O., THUNDIYIL, J.G. and STOLBACH, A. Clearing the air: a review of the effects of particulate matter air pollution on human health. Journal of Medical Toxicology. 2012, 8(2), 166-175. https://doi.org/10.1007/s13181-011-0203-1

BARBERÁN, A., et al. Continental-scale distributions of dust-associated bacteria and fungi. Proceedings of the National Academy of Sciences. 2015, 112(18), 5756-5761. https://doi.org/10.1073/pnas.1420815112 
BOWERS, R.M., MCLETCHIE, S., KNIGHT, R. and FIERER, N. Spatial variability in airborne bacterial communities across land-use types and their relationship to the bacterial communities of potential source environments. The ISME Journal. 2011, 5(4), 601-612.

https://doi.org/10.1038/ismej.2010.167

BROWN, J.K. and HOVM $\varnothing$ LLER, M.S. Aerial dispersal of pathogens on the global and continental scales and its impact on plant disease. Science. 2002, 297(5581), 537-541. https://doi.org/10.1126/science.1072678

CHASE, M.W. and FAY, M.F. Barcoding of plants and fungi. Science. 2009, 325(5941), 682-683.

https://www.science.org/doi/10.1126/science.1176906

DOUWES, J., THORNE, P., PEARCE, N. and HEEDERIK, D. Bioaerosol health effects and exposure assessment: progress and prospects. The Annals of occupational hygiene. 2003, 47(3), 187-200. https://doi.org/10.1093/annhyg/meg032

FICETOLA, G.F., et al. An in-silico approach for the evaluation of DNA barcodes. BMC Genomics. 2010, 11(1), 434. https://doi.org/10.1186/1471-2164-11-434

FRÖHLICH-NOWOISKY, J., et al. Biogeography in the air: fungal diversity over land and oceans. Biogeosciences. 2012, 9(3), 1125. https://doi.org/10.5194/bg-9-1125-2012

FRÖHLICH-NOWOISKY, J., PICKERSGILL, D.A., DESPRÉS, V.R. and PÖSCHL, U. High diversity of fungi in air particulate matter. Proceedings of the National Academy of Sciences. 2009, 106(31), 12814-12819. https://doi.org/10.1073/pnas.0811003106

GARDES, M. and BRUNS, T.D. ITS primers with enhanced specificity for basidiomycetes application to the identification of mycorrhizae and rusts. Molecular Ecology. 1993, 2(2), 113-118. https://doi.org/10.1111/j.1365-294X.1993.tb00005.x

HEBERT, P.D., CYWINSKA, A., BALL, S.L. and DEWAARD, J.R. Biological identifications through DNA barcodes. Proceedings of the Royal Society of London. Series B: Biological Sciences. 2003, 270(1512), 313-321. https://doi.org/10.1098/rspb.2002.2218

HINDS, W.C. Aerosol technology: properties, behavior, and measurement of airborne particles. 2nd ed. California: John Wiley \& Sons, 1999. Available from:

https://books.google.co.th/books?hl=en\&lr=\&id=4fJqDwAAQBAJ\&oi=fnd\&pg=PR11\&dq=.+Aerosol+technology:+properties, + behavior,+ and $+m$ easurement+of+airborne+particles\&ots=4Z8ervnY3F\&sig=Mybvdm0lhhLPW6tbtF_aDBhtjbo\&redir_esc=y\#v=onepage\&q=.\%20Aerosol\%20tech nology 3 A \%20properties\%2C\%20behavior\%2C\%20and\%20measurement\%20of\%20airborne\%20particles\&f=false

HOGG, J.C. and LEHANE, M.J. Identification of bacterial species associated with the sheep scab mite (Psoroptes ovis) by using amplified genes coding for 16S rRNA. Applied and Environmental Microbiology. 1999, 65(9), 4227-4229. https://doi.org/10.1128/AEM.65.9.4227-4229.1999

HUSSIN, N.H.M., SANN, L.M., SHAMSUDIN, M.N. and HASHIM, Z. Characterization of bacteria and fungi bioaerosol in the indoor air of selected primary schools in Malaysia. Indoor and Built Environment. 2011, 20(6), 607-617. https://doi.org/10.1177/1420326X11414318

KALOGERAKIS, N., et al. Indoor air quality-bioaerosol measurements in domestic and office premises. Journal of Aerosol Science. 2005, 36(5-6), 751-761. https://doi.org/10.1016/j.jaerosci.2005.02.004

KRESS, W.J. and ERICKSON, D.L. A two-locus global DNA barcode for land plants: the coding $r b c L$ gene complements the non-coding trnH-psbA spacer region. PLoS One. 2007, 2(6). https://doi.org/10.1371/journal.pone.0000508

LI, D.-Z., et al. Comparative analysis of a large dataset indicates that internal transcribed spacer (ITS) should be incorporated into the core barcode for seed plants. Proceedings of the National Academy of Sciences. 2011, 108(49), 19641. https://doi.org/10.1073/pnas.1104551108

LUO, A., et al. Potential efficacy of mitochondrial genes for animal DNA barcoding: a case study using eutherian mammals. BMC genomics. 2011, 12(1), 84. https://doi.org/10.1186/1471-2164-12-84

MAKI, T., et al. Variations in airborne bacterial communities at high altitudes over the Noto Peninsula (Japan) in response to Asian dust events. Atmospheric Chemistry \& Physics, 2017, 17(19). https://doi.org/10.5194/acp-17-11877-2017

NIJMAN, V. and ALIABADIAN, M. Performance of distance-based DNA barcoding in the molecular identification of Primates. Comptes rendus biologies. 2010, 333(1), 11-16. https://doi.org/10.1016/j.crvi.2009.10.003

SALVI, D. and MARIOTTINI, P. Molecular phylogenetics in 2D: ITS2 rRNA evolution and sequence-structure barcode from Veneridae to Bivalvia. Molecular phylogenetics and evolution. 2012, 65(2), 792-798. https://doi.org/10.1016/j.ympev.2012.07.017

SAMSET, B.H. Aerosols and climate: Oxford Research Encyclopedia of Climate Science. Oxford: Oxford University Press, 2016. https://doi.org/10.1093/acrefore/9780190228620.013.13

SMITH, M.A., et al. DNA barcodes affirm that 16 species of apparently generalist tropical parasitoid flies (Diptera, Tachinidae) are not all generalists. Proceedings of the National Academy of Sciences. 2007, 104(12), 4967. https://doi.org/10.1073/pnas.0700050104

SOLTIS, P.S., SOLTIS, D.E. and SMILEY, C.J. An rbcL sequence from a Miocene Taxodium (bald cypress). Proceedings of the National Academy of Sciences. 1992, 89(1), 449-451. https://doi.org/10.1073/pnas.89.1.449

SRIVASTAVA, A., SINGH, M. and JAIN, V.K. Identification and characterization of size-segregated bioaerosols at Jawaharlal Nehru University, New Delhi. Natural hazards. 2012, 60(2), 485-499. https://doi.org/10.1007/s11069-011-0022-3

STERN, R.F., et al. Evaluating the ribosomal internal transcribed spacer (ITS) as a candidate dinoflagellate barcode marker. PLoS One. 2012, 7(8), e42780. https://doi.org/10.1371/journal.pone.0042780 
TORSVIK, V., GOKS $\varnothing$ YR, J. and DAAE, F.L. High diversity in DNA of soil bacteria. Applied and Environmental Microbiology Journal. 1990, 56(3), 782-787. https://doi.org/10.1128/aem.56.3.782-787.1990

TURNER, S., PRYER, K.M., MIAO, V.P. and PALMER, J.D. Investigating deep phylogenetic relationships among cyanobacteria and plastids by small subunit rRNA sequence analysis. Journal of Eukaryotic Microbiology. 1999, 46(4), 327-338. https://doi.org/10.1111/j.15507408.1999.tb04612.x

VENCES, M., et al. Comparative performance of the 16S rRNA gene in DNA barcoding of amphibians. Frontiers in Zoology. $2005,2(1), 5$. https://doi.org/10.1186/1742-9994-2-5

WHITE, T.J., BRUNS, T., LEE, S. and TAYLOR, J., 1990. Amplification and direct sequencing of fungal ribosomal RNA genes for phylogenetics. In: INNIS, M.A., GELFAND, D.H., SNINSKY, J.J. and WHITE, T.J. (Eds.). PCR protocols: a guide to methods and applications. New York: Academic Press, Inc. pp. 315-322. Available from: https://msafungi.org/wp-content/uploads/2019/03/February-2013-Inoculum.pdf

WOMACK, A., et al. Characterization of active and total fungal communities in the atmosphere over the Amazon rainforest. Biogeosciences. 2015, 12(21), 6337-6349. https://doi.org/10.5194/bg-12-6337-2015

Received: 14 April 2020 | Accepted: 3 September 2021 | Published: 29 December 2021

This is an Open Access article distributed under the terms of the Creative Commons Attribution License, which permits unrestricted use, distribution, and reproduction in any medium, provided the original work is properly cited. 